\title{
Proton-Electron Transfer to the Active Site Is Essential for the Reaction Mechanism of Soluble $\Delta^{9}$-Desaturase.
}

\author{
Supporting Information.
}

\author{
Daniel Bím, ${ }^{a, b}$ Jakub Chalupský, ${ }^{b}$ Martin Culka, ${ }^{b}$ Edward I. Solomon, ${ }^{c}$ Lubomír Rulíšek, ${ }^{b, *}$ \\ and Martin Srnec ${ }^{a, *}$
}

aJ. Heyrovský Institute of Physical Chemistry, The Czech Academy of Sciences, Dolejškova 3, Prague 8 182 23, Czech Republic

${ }^{b}$ Institute of Organic Chemistry and Biochemistry, The Czech Academy of Sciences, Flemingovo nám. 2, Prague 6166 10, Czech Republic

'Department of Chemistry, Stanford University, 333 Campus Drive, Stanford, California 94305-5080, United States

\section{Supporting Information Contents}

Additional details of the protein preparation for the QM/MM p. S2

$\begin{array}{ll}\text { Supplementary Tables S1-S3 } & \text { p. S3-S5 }\end{array}$

$\begin{array}{ll}\text { Supplementary Figures S1-S9 p. S6-S27 } & \text { p. }\end{array}$

Full structure of the $\mathbf{P}$ intermediate used for QM/MM optimizations is attached as a separate pdb file. 


\section{Additional details of the protein preparation for the QM/MM}

\section{Hydrogen atoms and protonation states}

Hydrogen atoms were added by the leap module of the AMBER program, assuming that all Asp and Glu residues are negatively charged and all Lys and Arg residues are positively charged. For each monomer, the protonation states of the His residues were determined by a study of the hydrogen-bonding pattern, the surroundings, and the solvent exposure of each residue: His25, 213, 281 were assumed to be protonated on the $\mathrm{N} \delta$ atom, His146, 232 on the $\mathrm{N} \varepsilon$ atom, and the remaining eight histidines (His30, 54, 268) at both nitrogen atoms, thus bearing a positive charge (residues are numbered according to the 1AFR crystal structure). The His203 residue (part of the QM region) changes its protonation state along the reaction coordinate in pathways $1 \mathrm{a}$ and $1 \mathrm{c}$ that requires an additional proton transfer into the active site of the enzyme. It can be mentioned that the crystal structure was determined at $\mathrm{pH} 6.5$.

\section{Simulated annealing}

Because of the absence of the X-ray structure of the [protein...substrate] complex, a simplified substrate model (i.e., $\mathrm{CH}_{3}-\left(\mathrm{CH}_{2}\right)_{16}-\mathrm{COO}-$ phosphopantetheine linker capped by a methyl group instead of an acyl carrier protein) was docked manually into the substrate entrance channel of the $\Delta^{9} \mathrm{D}$. The position was refined by simulated annealing of eight different initial substrate conformations (vide supra). The protein-substrate complex was then solvated in a shell of explicit TIP3P water molecules with a thickness

of $10 \AA$ which resulted in an addition of approximately 6900 water molecules yielding a total number of 32000 atoms in the simulations. The positions of all hydrogen atoms, added water molecules, and substrate were first minimized and then equilibrated for 300 ps using a simulated annealing protocol (heating the system to $370 \mathrm{~K}$ and cooling it slowly down to $0 \mathrm{~K}$ ), keeping all remaining atoms at the original positions. 
Table S1. Energetics of the direct $\mathrm{C}-\mathrm{H}$ bond activation pathway from the $\mathbf{P}$ intermediate. Energies are calculated at the QM(B3LYP*-D3)/MM level of theory.

\begin{tabular}{|c|c|c|}
\hline & $\begin{array}{c}\Delta E \text { (above } \mathbf{P} \text { intermediate) } \\
{\left[\mathrm{kcal} \mathrm{mol}^{-1}\right]}\end{array}$ & $\begin{array}{c}\text { Coordinates of the QM region of } \\
\text { the QM/MM optimized structure } \\
\text { in the attached zip file }\end{array}$ \\
\hline \multicolumn{3}{|l|}{ Stepwise } \\
\hline$i . \mathrm{TS}_{(\mathrm{C}-\mathrm{H} \text { cleavage })}$ & 26.9 & 01_direct_stepwiseA_TS1.xyz \\
\hline Intermediate & 24.0 & 02_direct_stepwiseA_int.xyz \\
\hline $\mathrm{TS}^{2}(\mathrm{O}-\mathrm{O}$ cleavage $)$ & 36.3 & 03 direct_stepwiseA_TS2.xyz \\
\hline ii. $\mathrm{TS}^{1}(\mathrm{O}-\mathrm{O}$ cleavage $)$ & 24.6 & 04_direct_stepwiseB_TS1.xyz \\
\hline Intermediate & 11.7 & 05_direct_stepwiseB_int.xyz \\
\hline $\mathrm{TS}^{2}(\mathrm{C}-\mathrm{H}$ cleavage $)$ & 21.9 & 06 direct_stepwiseB_TS2.xyz \\
\hline \multicolumn{3}{|l|}{ Concerted } \\
\hline $\mathrm{TS}$ & 25.2 & 08_direct_concerted_TS.xyz \\
\hline
\end{tabular}

Table S2. Mulliken spin densities of selected atoms as calculated for the active intermediate and transition state structures for the three studied activation pathways $\left(\mathbf{1 a}, \mathbf{1 b}\right.$, and $\mathbf{1 c}$ in the main text). ${ }^{\mathrm{a}}$

\begin{tabular}{lcccccccccc}
\hline \multicolumn{9}{c}{ Actived intermediate } & \multicolumn{5}{c}{ TS $^{1}$} \\
& $\mathrm{Fe}_{\mathrm{A}}$ & $\mathrm{Fe}_{\mathrm{B}}$ & $\mathrm{O}_{\mathrm{A}}$ & $\mathrm{O}_{\mathrm{B}}$ & $\mathrm{C}_{10}$ & $\mathrm{Fe}_{\mathrm{A}}$ & $\mathrm{Fe}_{\mathrm{B}}$ & $\mathrm{O}_{\mathrm{A}}$ & $\mathrm{O}_{\mathrm{B}}$ & $\mathrm{C}_{10}$ \\
\hline P' of 1a & -3.98 & 4.07 & 0.14 & 0.12 & 0.00 & -4.00 & 4.08 & 0.03 & 0.01 & 0.04 \\
$\mathbf{Q}$ of 1b & -3.05 & 3.02 & -0.32 & 0.42 & 0.00 & -3.08 & 3.71 & -0.32 & 0.02 & -0.33 \\
$\mathbf{X}$ of 1c & -3.03 & 4.11 & 0.33 & -0.65 & 0.00 & -3.71 & 4.11 & 0.32 & -0.28 & 0.36
\end{tabular}

${ }^{a}$ The atom labeling corresponds to Figures 5, 7, and 8 in the main text. Mulliken spin densities are obtained at the QM(TPSS)/MM level of theory (see Computational Details). 
Table S3. Raw energetic data of all pathways.

\begin{tabular}{|c|c|c|c|c|c|}
\hline & $\begin{array}{c}E \text { [a.u.] } \\
\text { QM(B3LYP*-D3)/MM }\end{array}$ & $\begin{array}{c}\Delta E\left[\mathrm{kcal} \mathrm{mol}^{-1}\right] \\
\mathrm{QM}\left(\mathrm{B} 3 \mathrm{LYP}^{*}{ }_{-}\right. \\
\text {D3)/MM }\end{array}$ & $\begin{array}{c}\Delta E\left[\mathrm{kcal} \mathrm{mol}^{-1}\right] \\
\mathrm{QM}(\mathrm{CASPT} 2) / \mathrm{MM}\end{array}$ & $\begin{array}{c}\Delta E\left[\mathrm{kcal} \mathrm{mol}^{-1}\right] \\
\mathrm{QM}(\mathrm{MC}- \\
\mathrm{PDFT}) / \mathrm{MM}\end{array}$ & $\begin{array}{l}\text { Coordinates of the } \\
\text { QM region of the } \\
\text { QM/MM optimized } \\
\text { structure in the } \\
\text { attached zip file }\end{array}$ \\
\hline \multicolumn{6}{|l|}{ 1a pathway } \\
\hline $\mathbf{P}$ & -7285.4576 & 0.0 & 0.0 & 0.0 & 09_1a_P.xyz \\
\hline $1 \mathbf{a}_{1}$ & -7285.9257 & 8.1 & - & - & 10_1a_1a1.xyz \\
\hline $\mathbf{P}^{\prime}$ & -7285.9181 & 12.8 & 0.6 & $2.5-3.7$ & 11_1a_P'.xyz \\
\hline $\mathbf{P}^{\prime} / \mathrm{TS}^{1}$ & -7285.8865 & 32.7 & 21.3 & $22.2-25.1$ & 12_1a_P'_TS1.xyz \\
\hline $\mathbf{P}$ '/int & -7285.9508 & -7.7 & - & - & 13_1a_P'_int.xyz \\
\hline P'/desaturated & -7286.0417 & -64.7 & - & - & 14_1a_P'_desat.xyz \\
\hline P'/hydroxylated & -7286.0360 & -61.1 & - & - & 15_1a_P'_hydrox.xyz \\
\hline \multicolumn{6}{|l|}{1 lb pathway } \\
\hline $\mathbf{P}$ & -7285.4576 & 0.0 & 0.0 & 0.0 & 09_1a_P.xyz \\
\hline $\mathbf{Q}$ & -7285.4274 & 19.0 & 9.6 & $12.5-18.5$ & 16_1b_Q.xyz \\
\hline $\mathbf{Q} / \mathrm{TS}^{1}$ & -7285.4122 & 28.5 & 23.3 & $34.8-40.3$ & 17_1b_Q_TS1.xyz \\
\hline $\mathbf{Q} /$ int & -7285.4360 & 13.6 & - & - & 18_1b_Q_int.xyz \\
\hline $\mathbf{Q} / \mathrm{TS}^{2}$ & -7285.4243 & 20.9 & - & - & 19_1b_Q_TS2.xyz \\
\hline $\mathbf{Q} /$ desaturated & -7285.5140 & -35.4 & - & - & 20_1b_Q_desat.xyz \\
\hline \multicolumn{6}{|l|}{ 1c pathway } \\
\hline $\mathbf{P}$ & -7285.4576 & 0.0 & - & - & 09_1a_P.xyz \\
\hline $1 \mathbf{a}_{1}$ & -7285.9257 & 8.1 & - & - & 10_1a_1a1.xyz \\
\hline $\mathbf{P}^{\prime}$ & -7285.9181 & 12.8 & - & - & 11_1a_P'.xyz \\
\hline $\mathbf{X}$ & -7286.0802 & 4.0 & 4.0 & 4.0 & 21_1c_X.xyz \\
\hline
\end{tabular}




\begin{tabular}{|c|c|c|c|c|c|}
\hline $\mathbf{X} / \mathrm{TS}^{1}$ & -7286.0655 & 13.3 & 14.2 & $14.7-17.3$ & 22_1c_X_TS1.xyz \\
\hline $\mathbf{X} /$ int $^{1}$ & -7286.0935 & -4.3 & 5.0 & $2.6-5.5$ & 23_1c_X_int1.xyz \\
\hline $\mathbf{X} / \mathrm{TS}^{2}$ & -7286.0827 & 2.4 & - & - & 28_1c_X_TS2.xyz \\
\hline $\mathrm{X} /$ desaturated & -7286.1465 & -37.6 & - & - & 29_1c_X_desat.xyz \\
\hline
\end{tabular}


Figure S1. $\Delta^{9}$ D model utilized in the calculations. Left: The region highlighted in yellow, green, and red correspond to System 1, System 2, and System 3 as specified in the Computational Details section. The System 1 is treated at the QM (DFT) level, System 2 is treated at the MM level, and System 3 is frozen at the crystallographic positions (except for water molecules that were subjected to MD-simulated annealing and then frozen in the QM/MM calculations). Right: System 1 (QM region) of the QM/MM calculations. Note that the full pdb structure of the $\mathbf{P}$ intermediate used for QM/MM optimizations is attached as a separate text file.
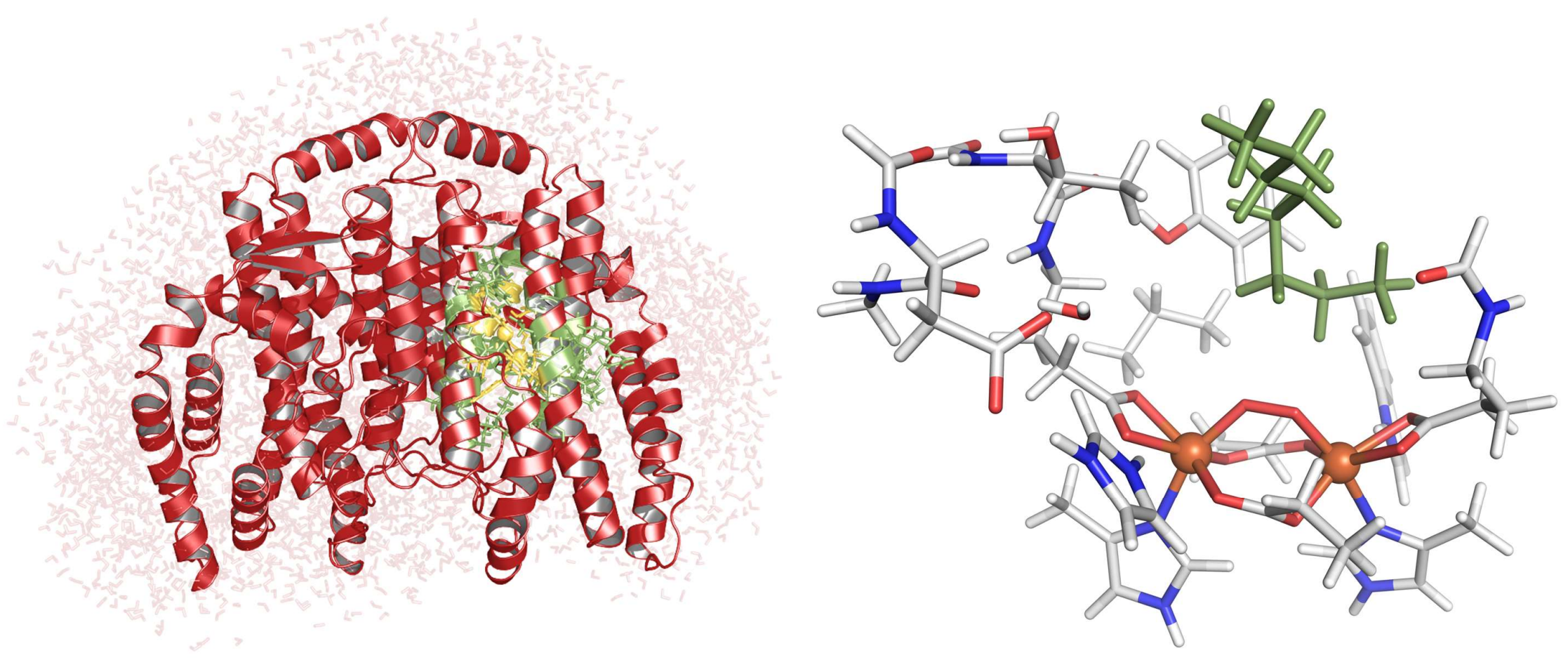
Figure S2. Molecular-orbital diagram given for the structure of the $\mathbf{P}$ intermediate. The complete active space consists of 22 electrons in 18 orbitals, denoted as $(22 \mathrm{e}, 18 \mathrm{o})$.

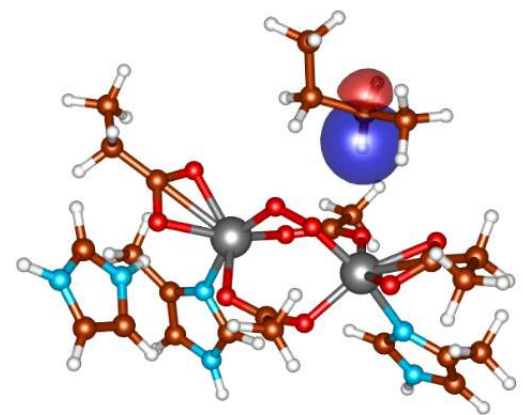

1.98

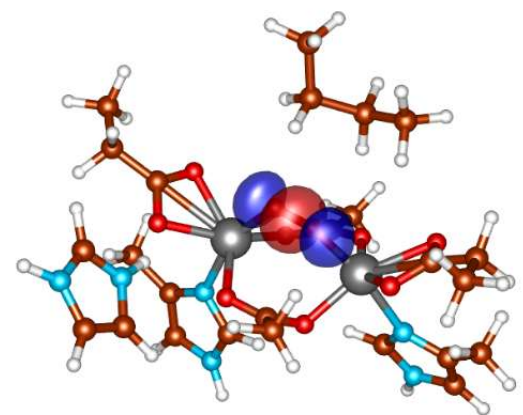

1.96

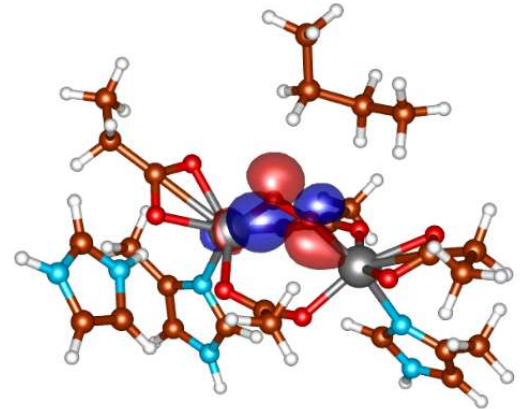

2.00

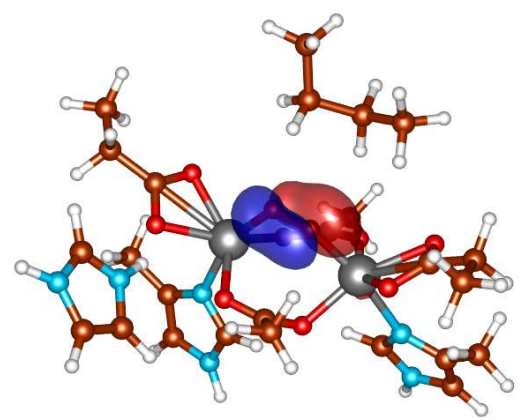

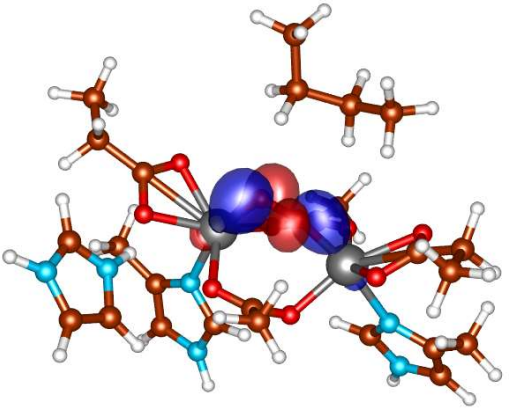

2.00

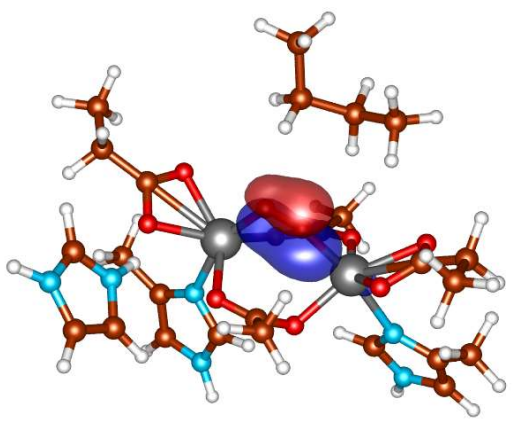


2.00

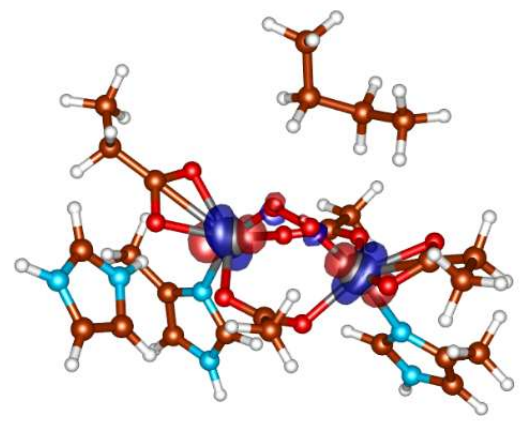

1.07

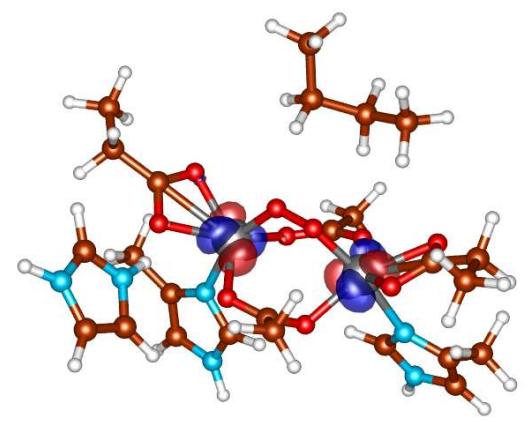

1.00

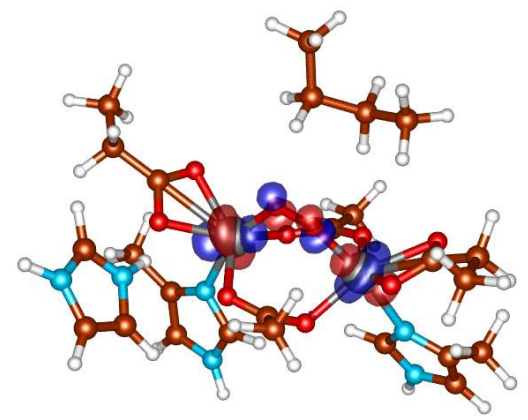

0.94

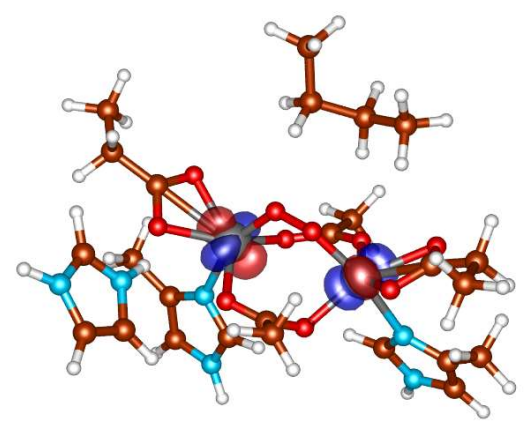

2.00

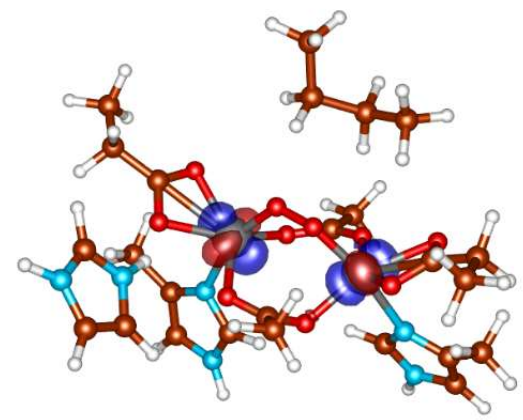

0.99

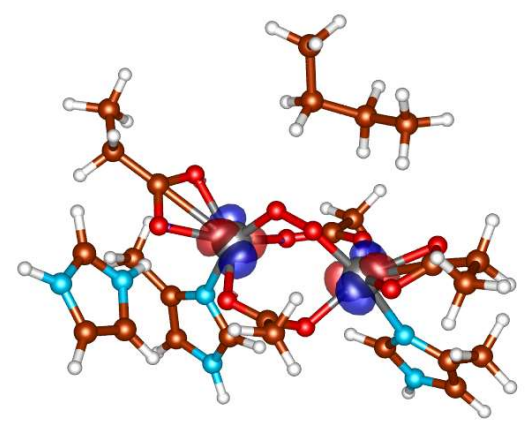

1.00

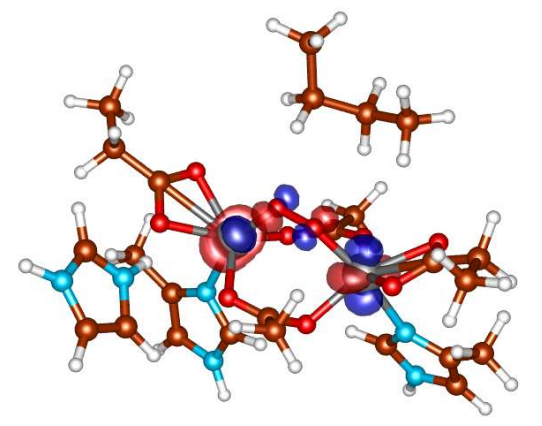

0.95

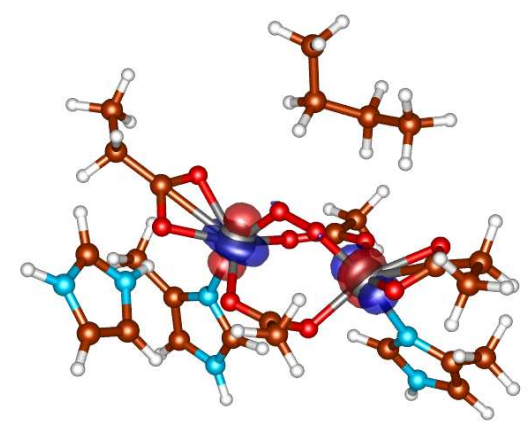


1.01

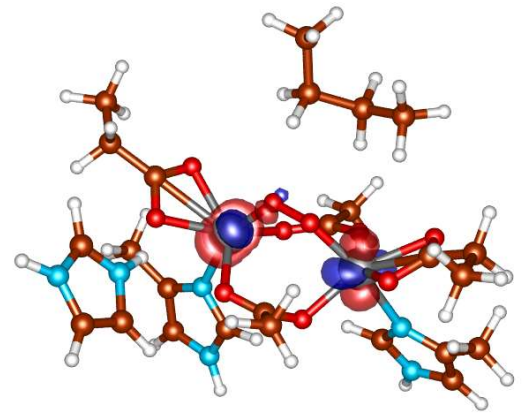

1.05
0.99

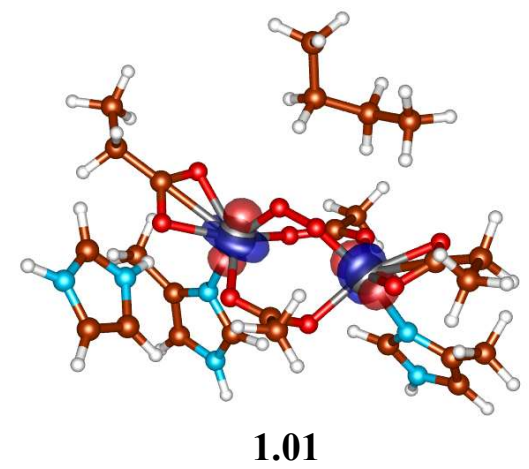

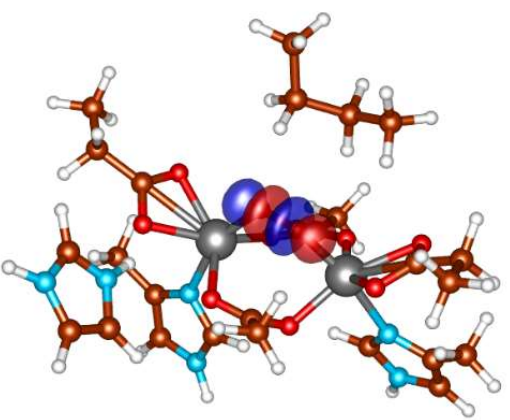

0.04

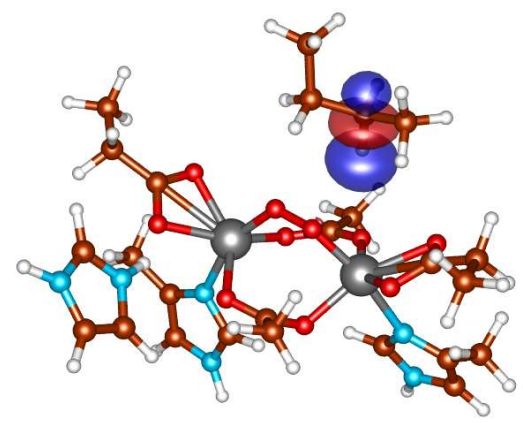

0.02 
Figure S3. Key geometric parameters for structures along all of the studied reaction pathways 1a, 1b, and 1c. Structures were optimized at the QM(TPSS-D3)/MM level of theory.
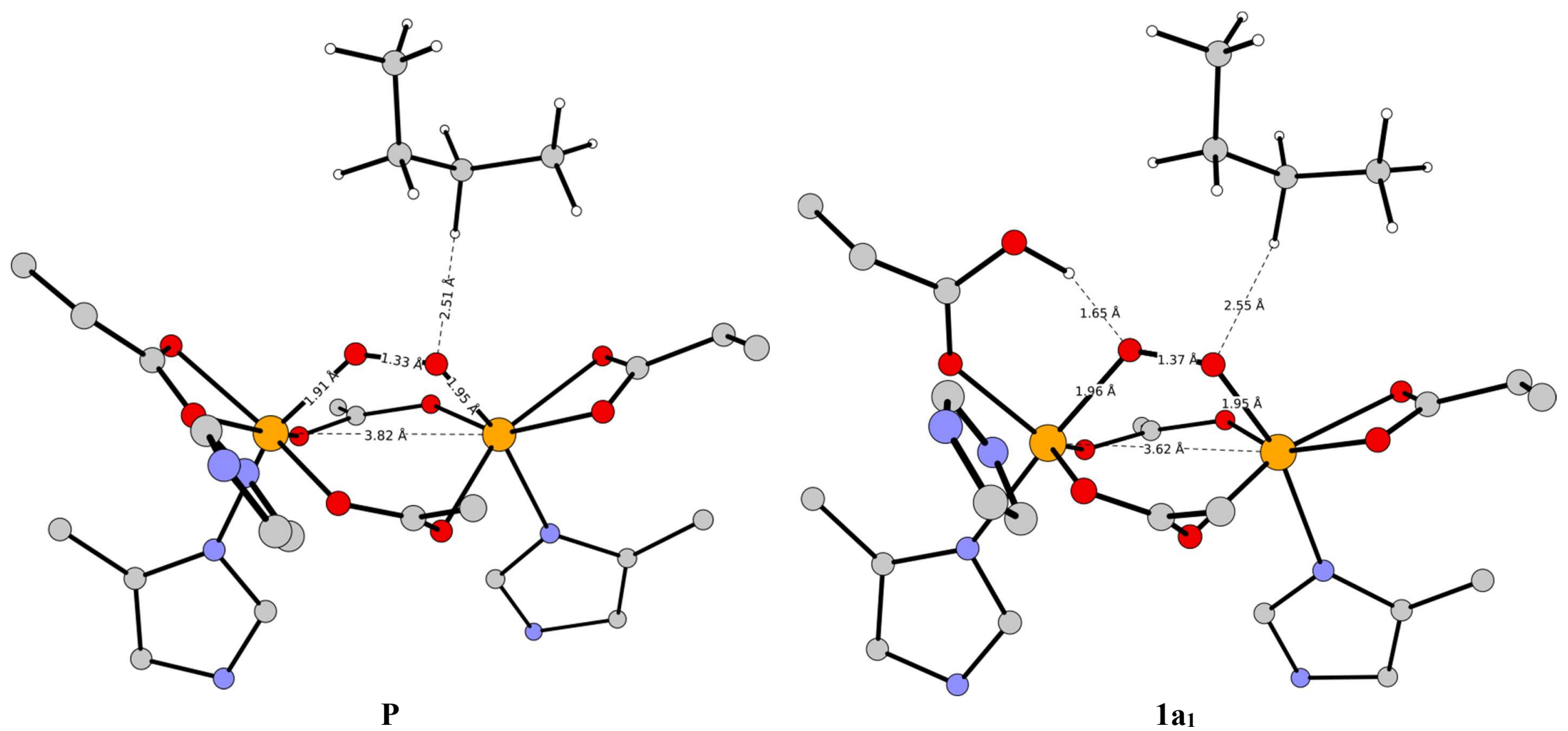


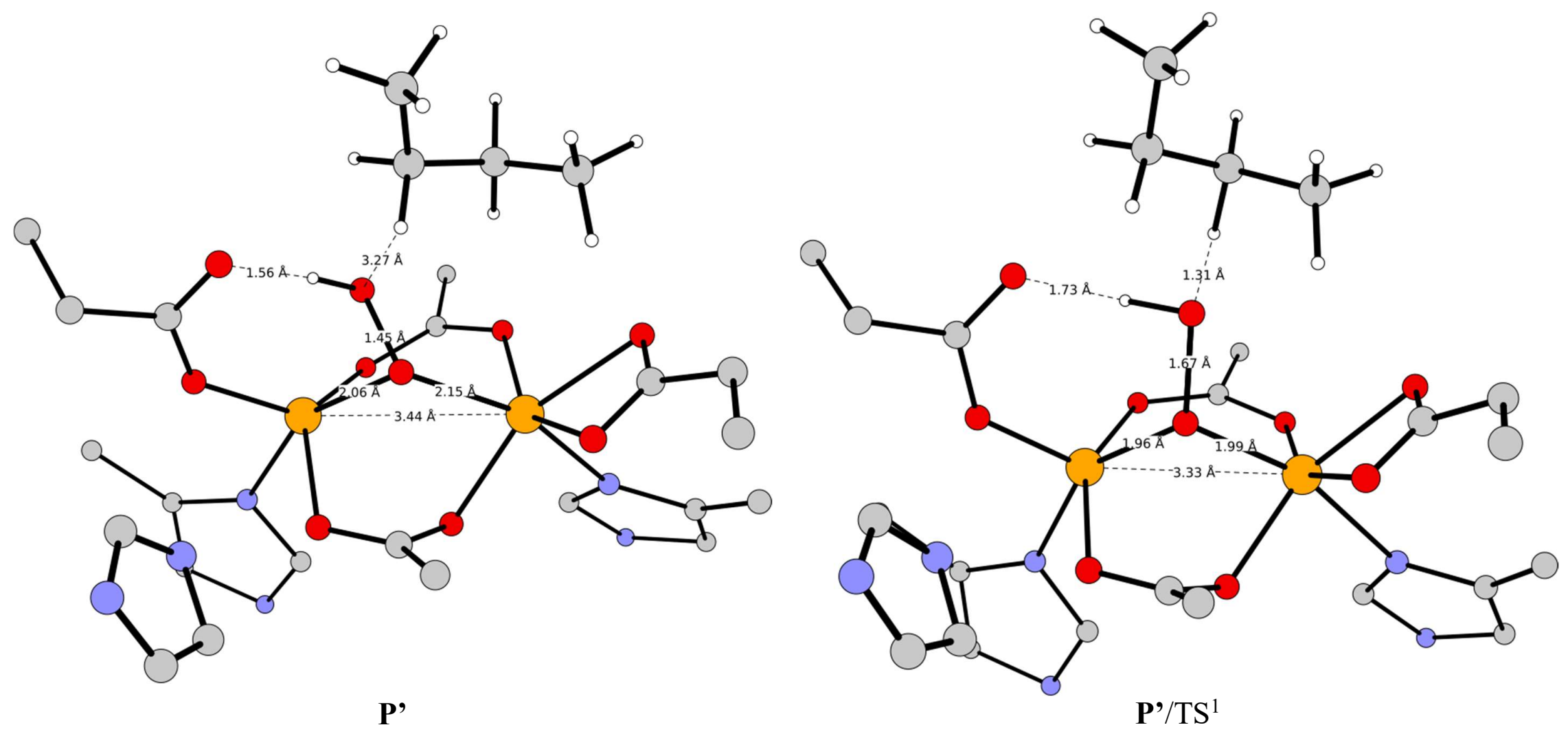

S11 

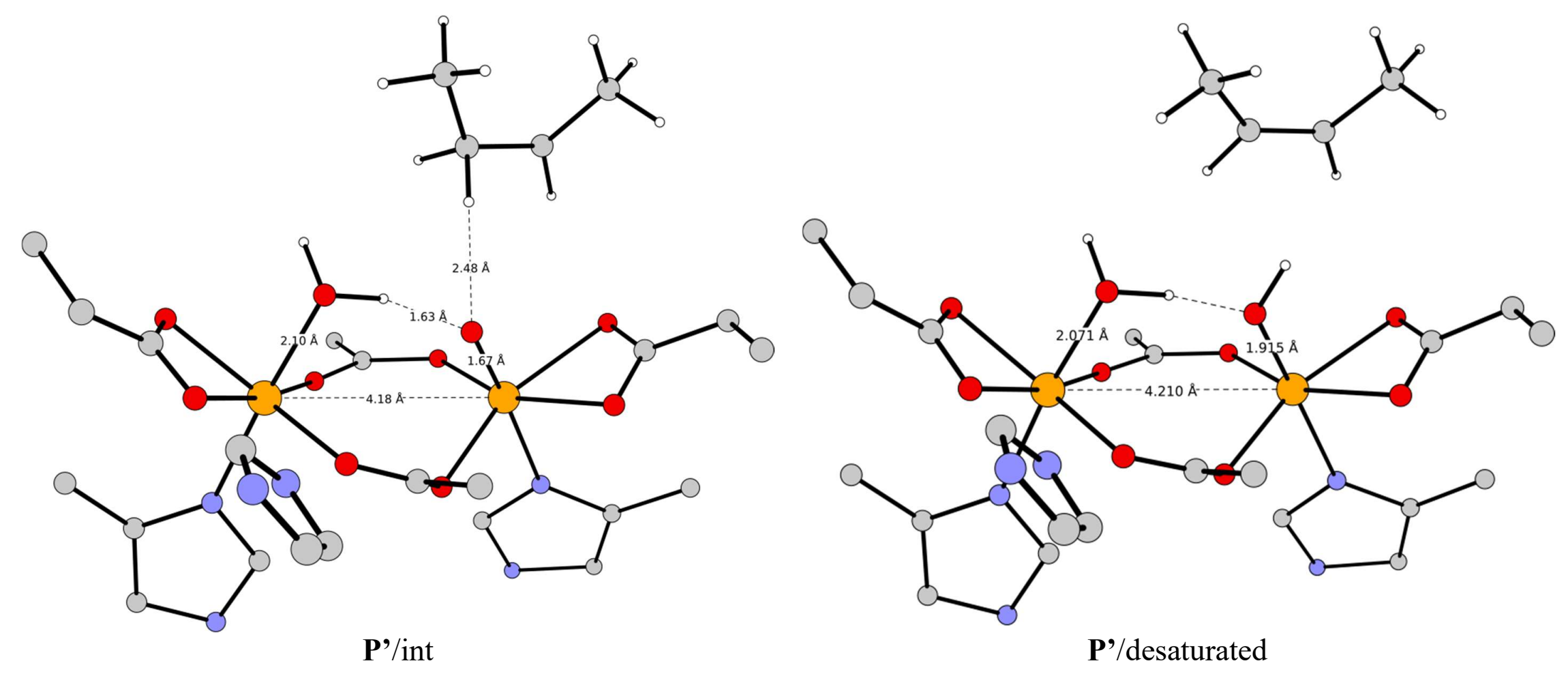


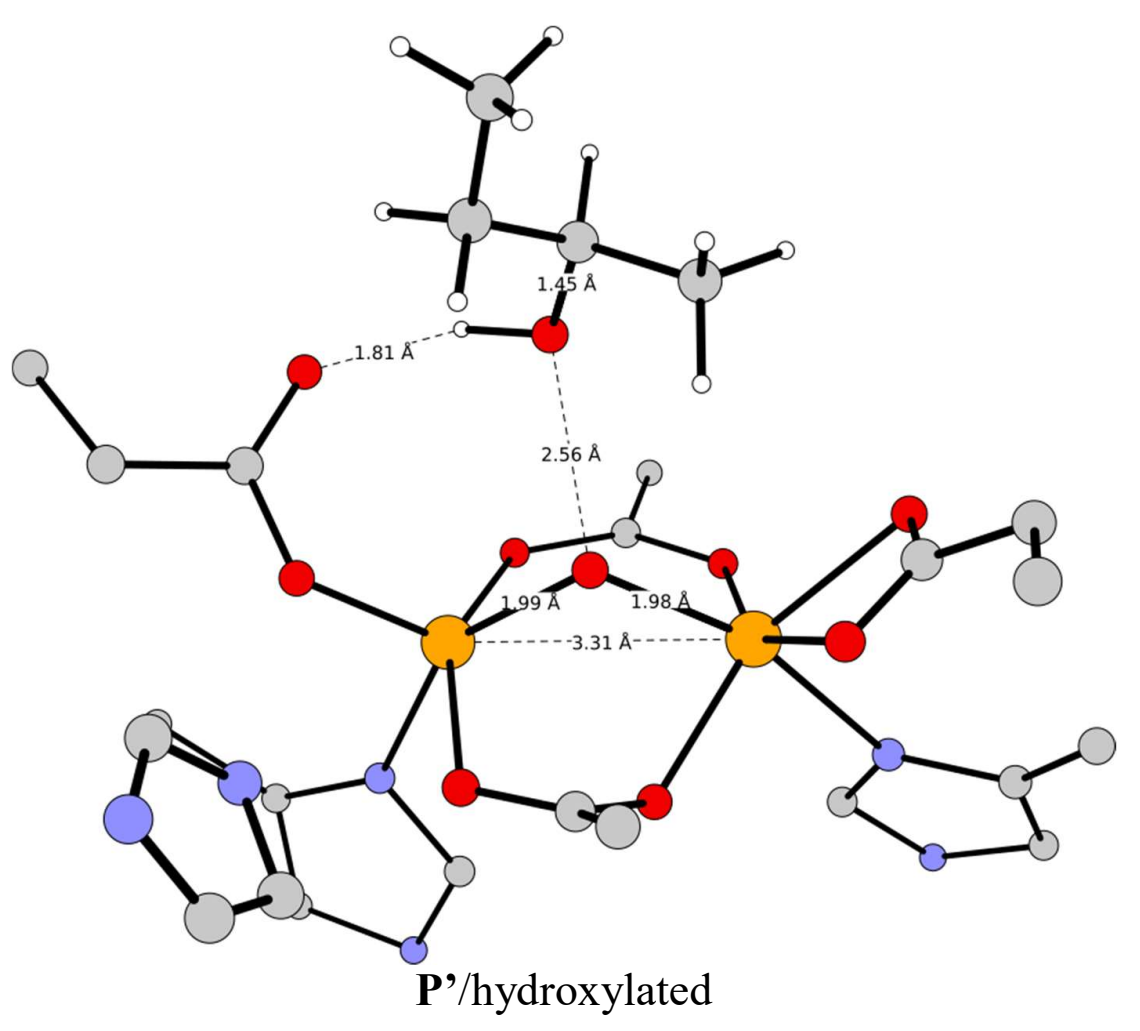



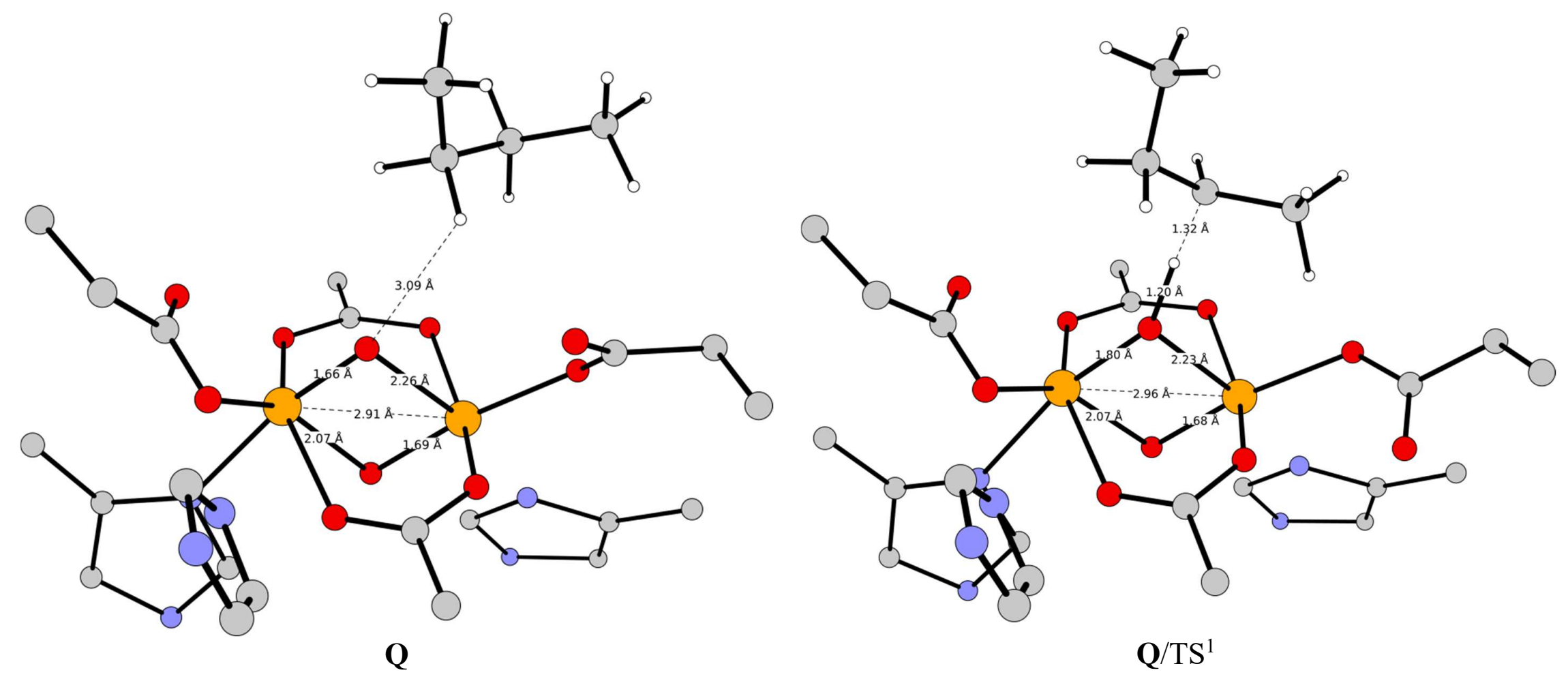


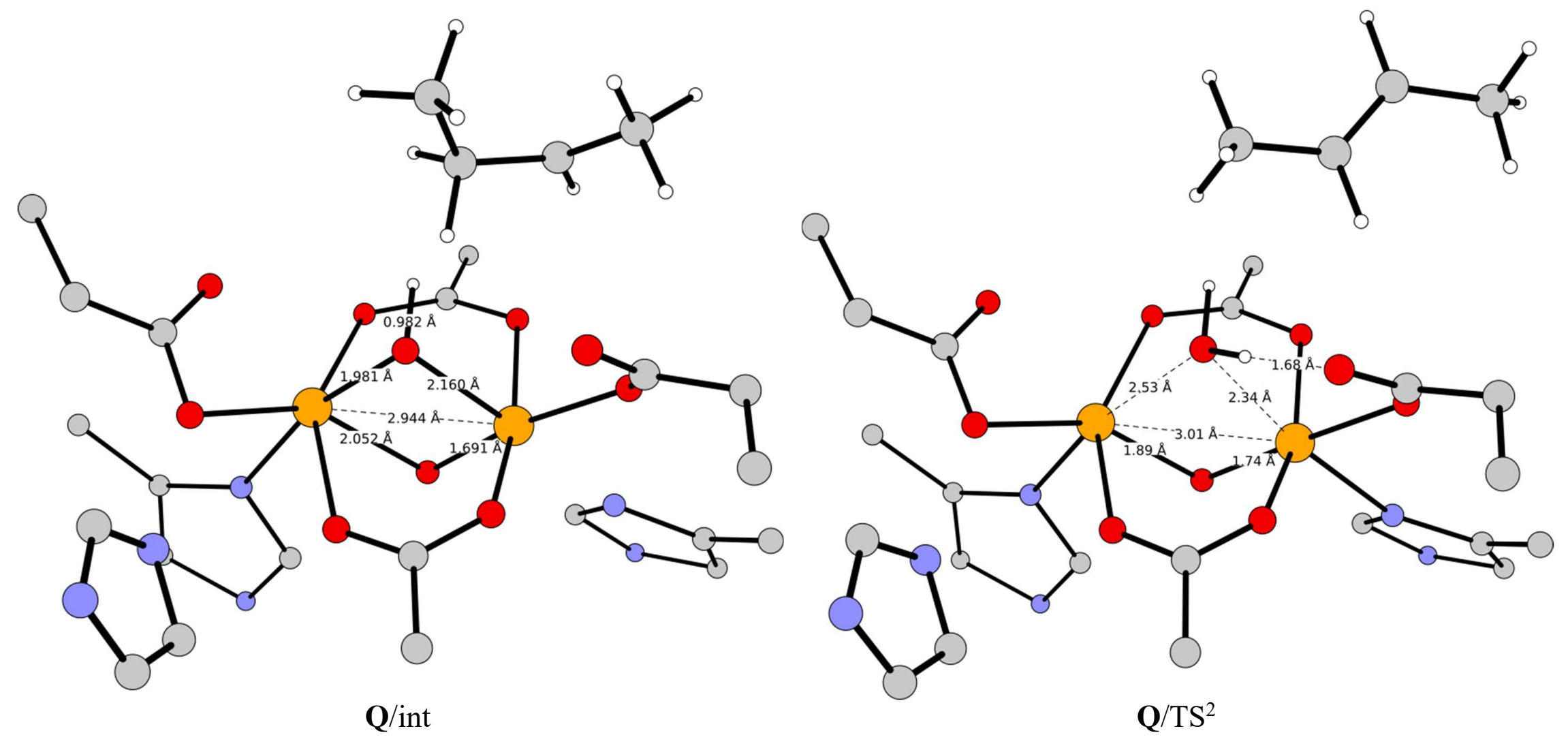



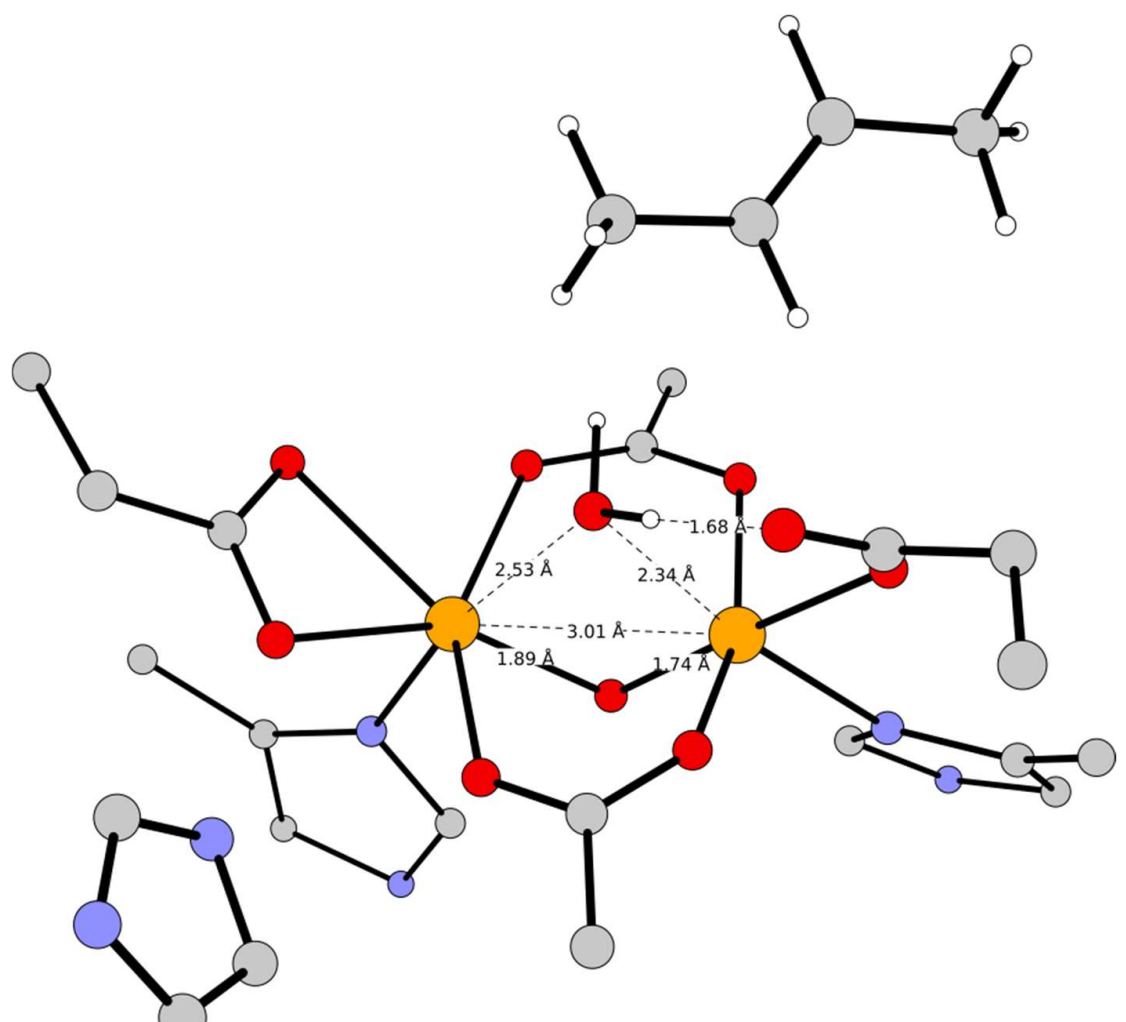

Q/desaturated 


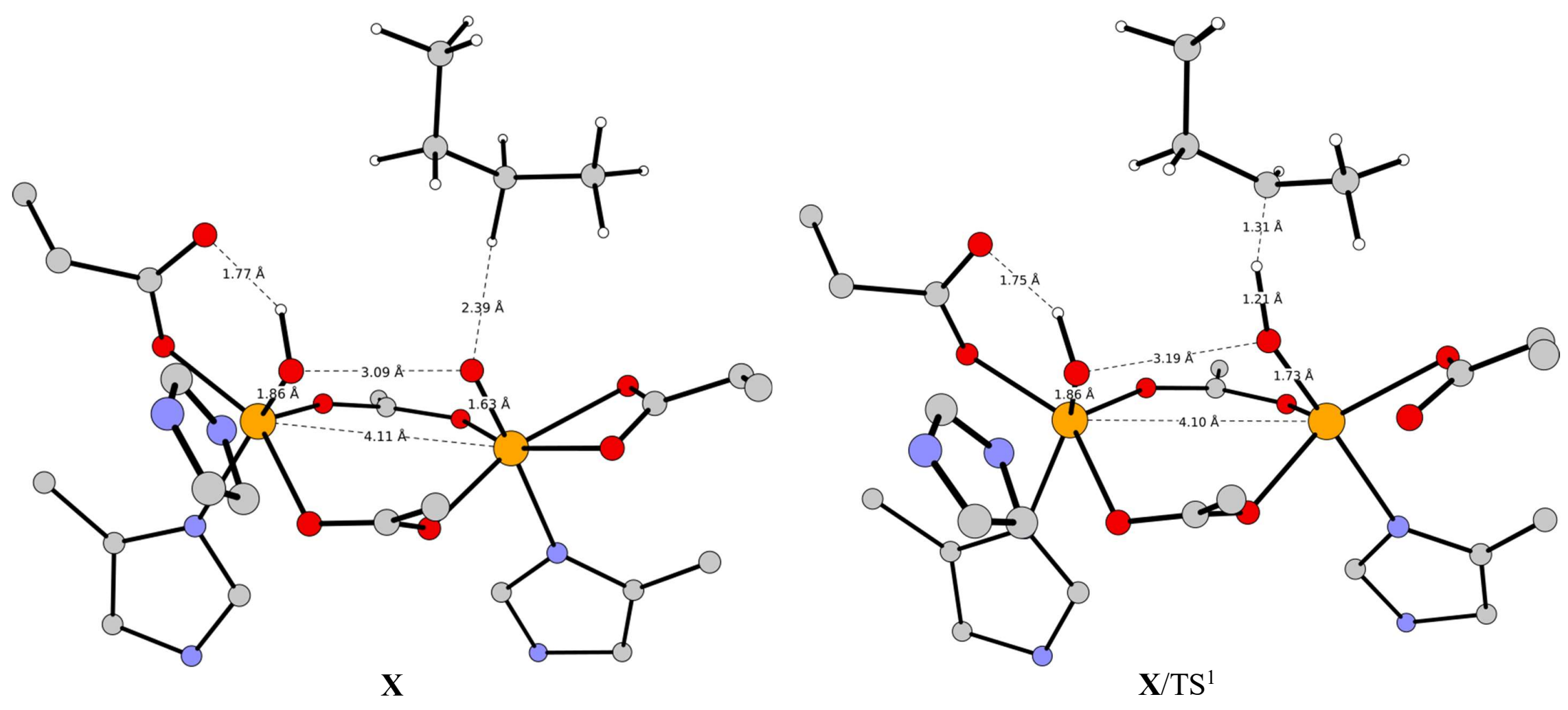

S17 

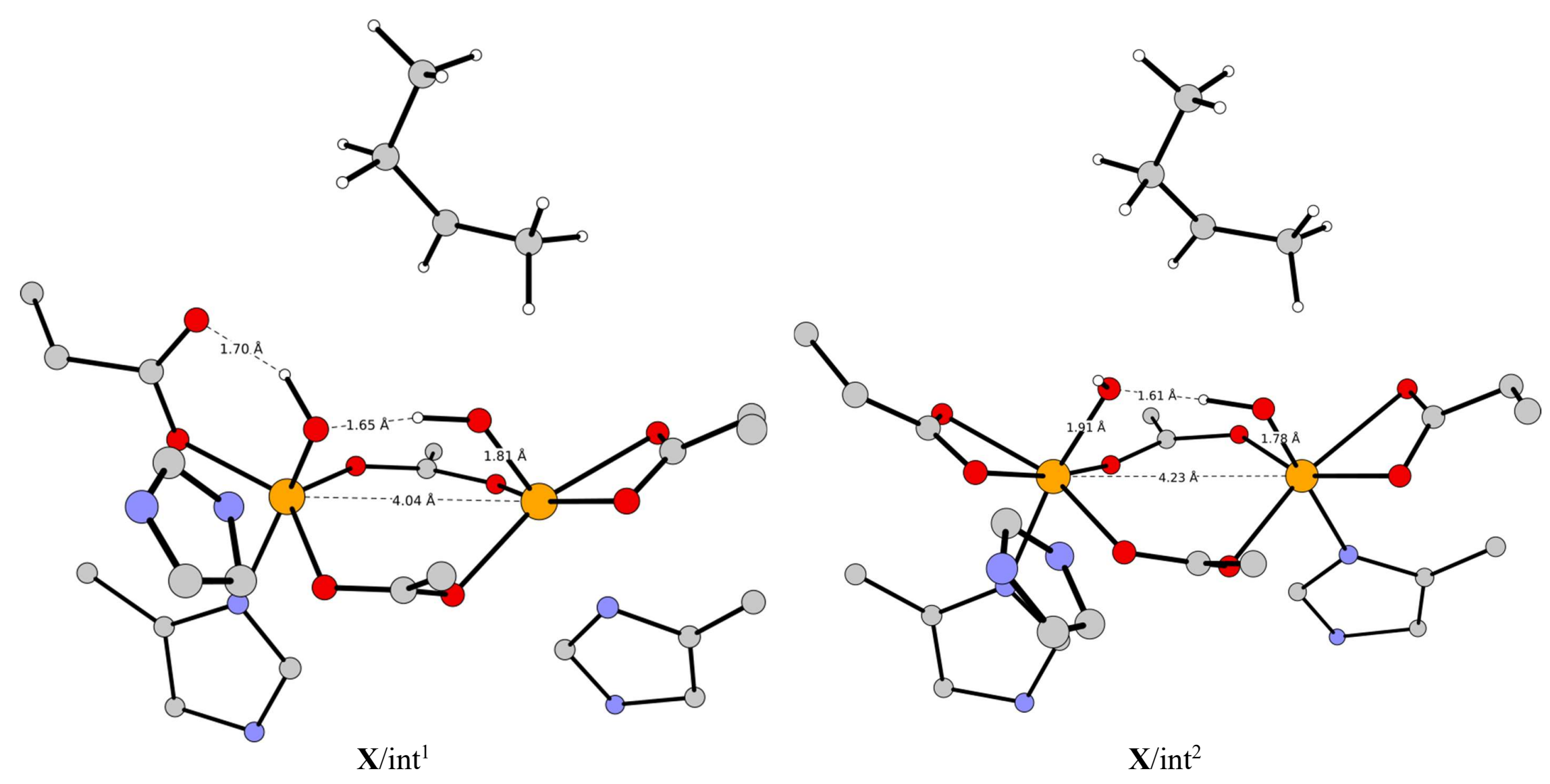

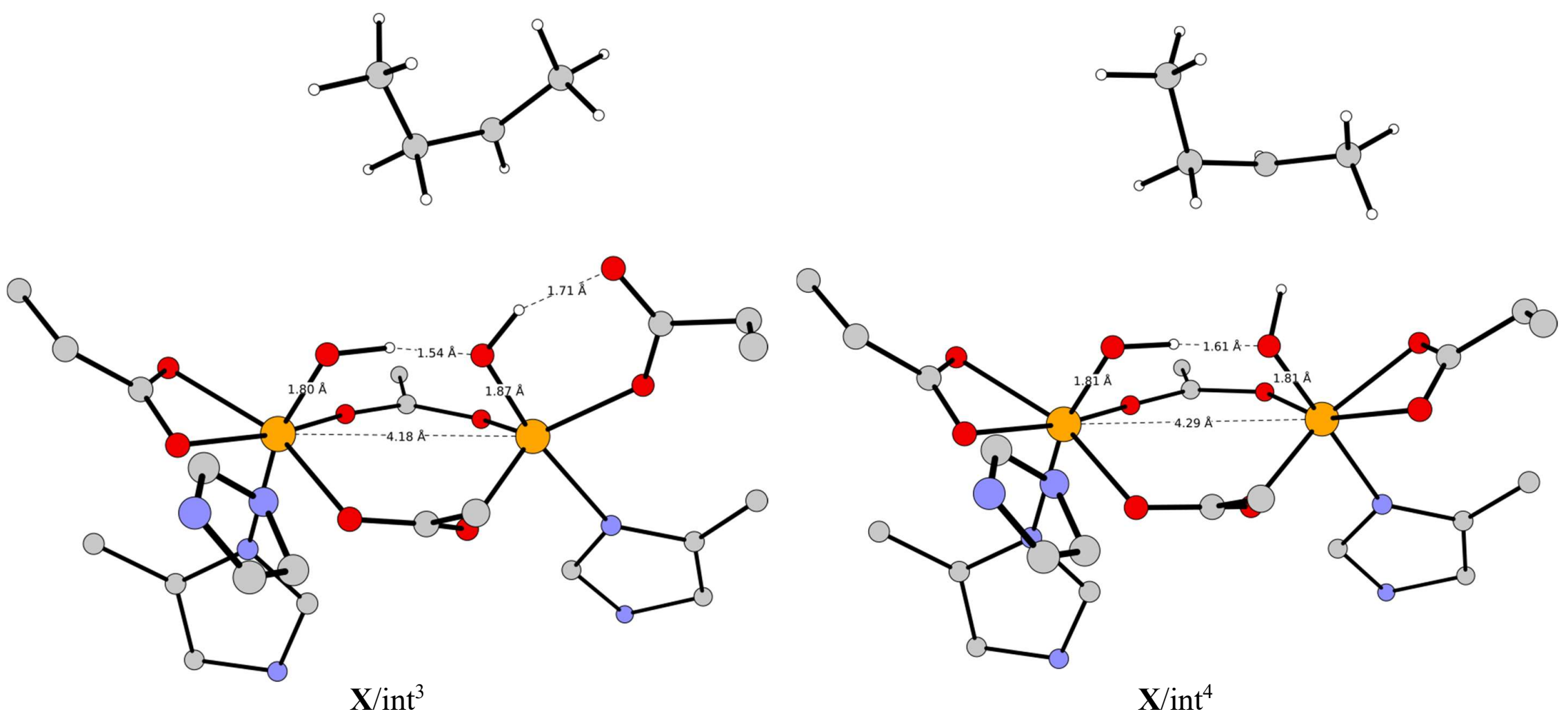

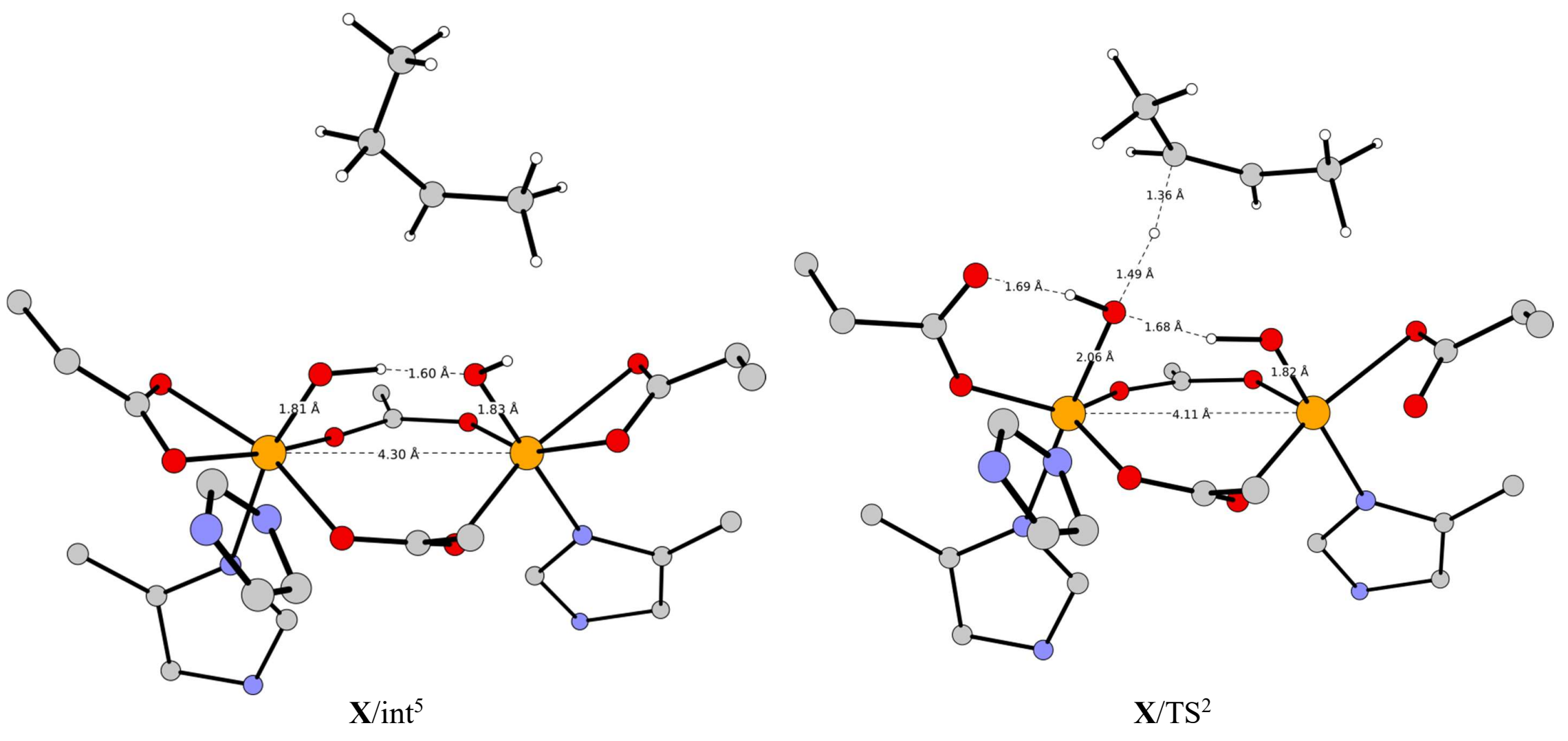

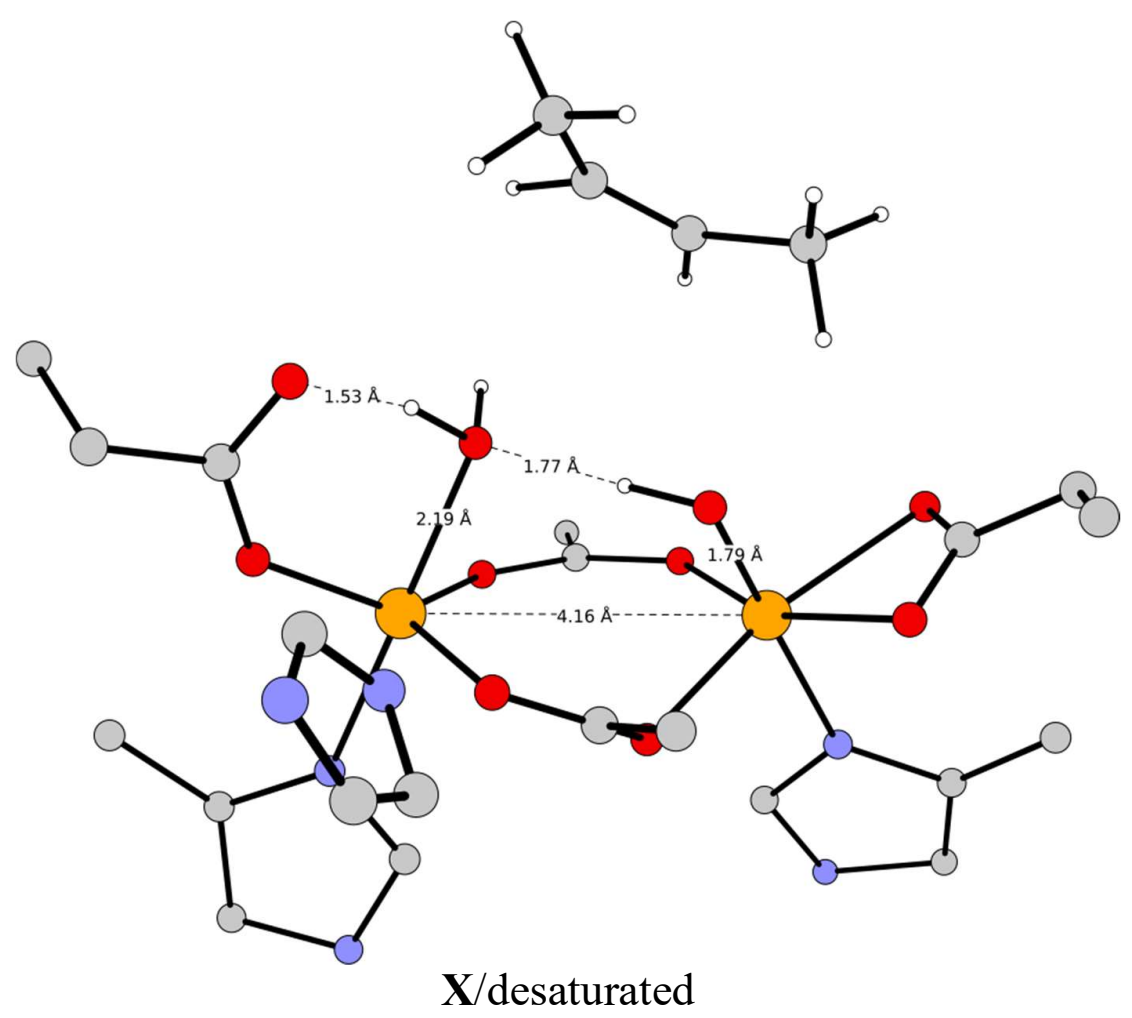
Figure S4. Multiple sequence alignment (using Clustal omega algorithm - see Computational Details section) of core regions of acyl-ACP desaturases originating from plants (first listed desaturase from Ricinus communis is the subject of this paper), archaea and bacteria. Pairwise sequence identity relative to Ricinus communis is $92-26 \%$. Important conserved residues are highlighted by arrows and numbered according to Ricinus communis sequence.

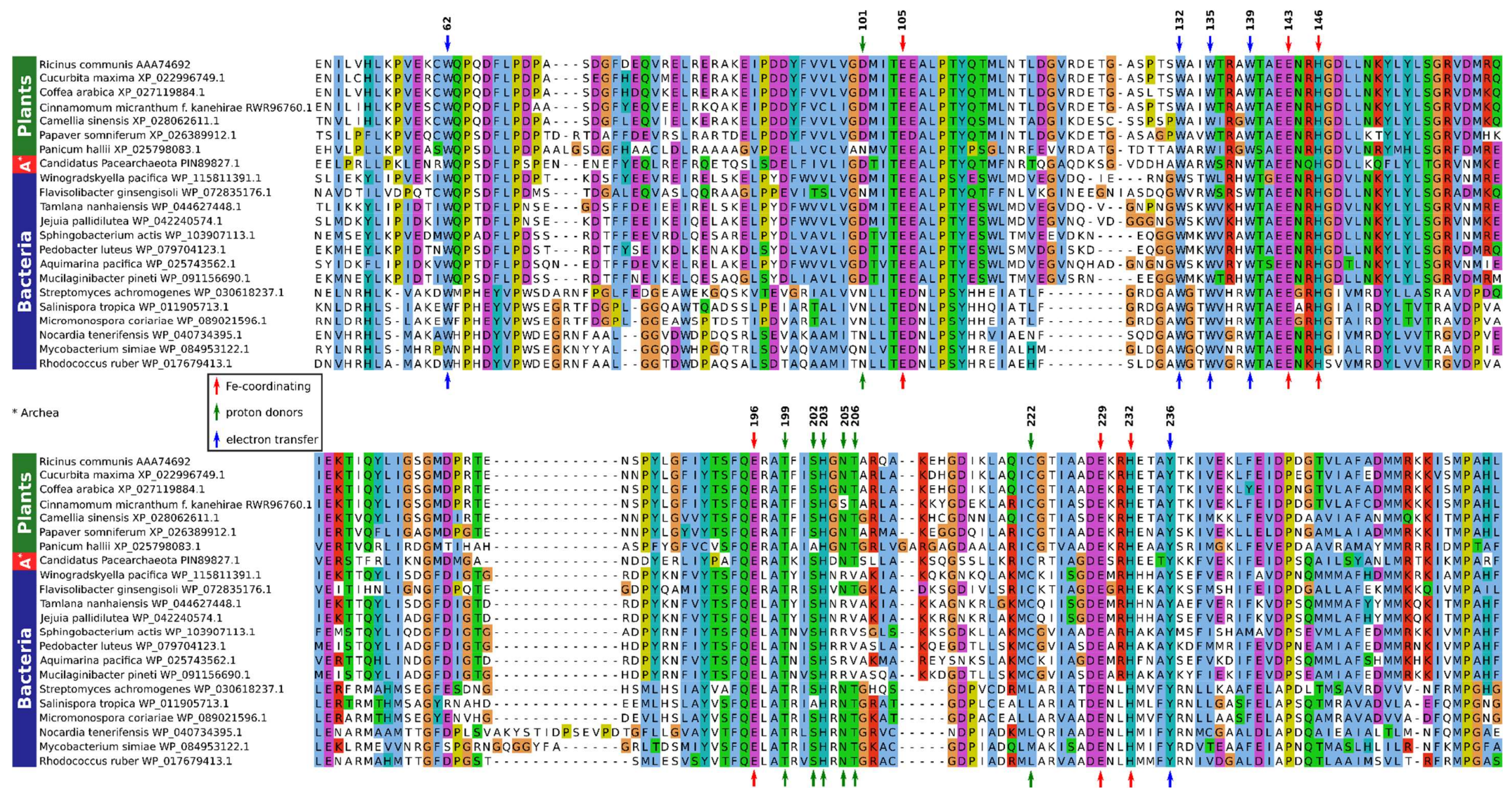


Figure S5. Suggested proton-transporting chains in the $\Delta^{9} \mathrm{D}$. Residues involved in a transfer of proton from bulk solvent to the $\Delta^{9} \mathrm{D}$ active site are highlighted, and the two possible proton-transfer mechanisms are indicated by the black arrows: i) His203 - Asp101 - Thr206 - Cys222, and ii) His203 - Asp101 - Ser202 - Asp296.

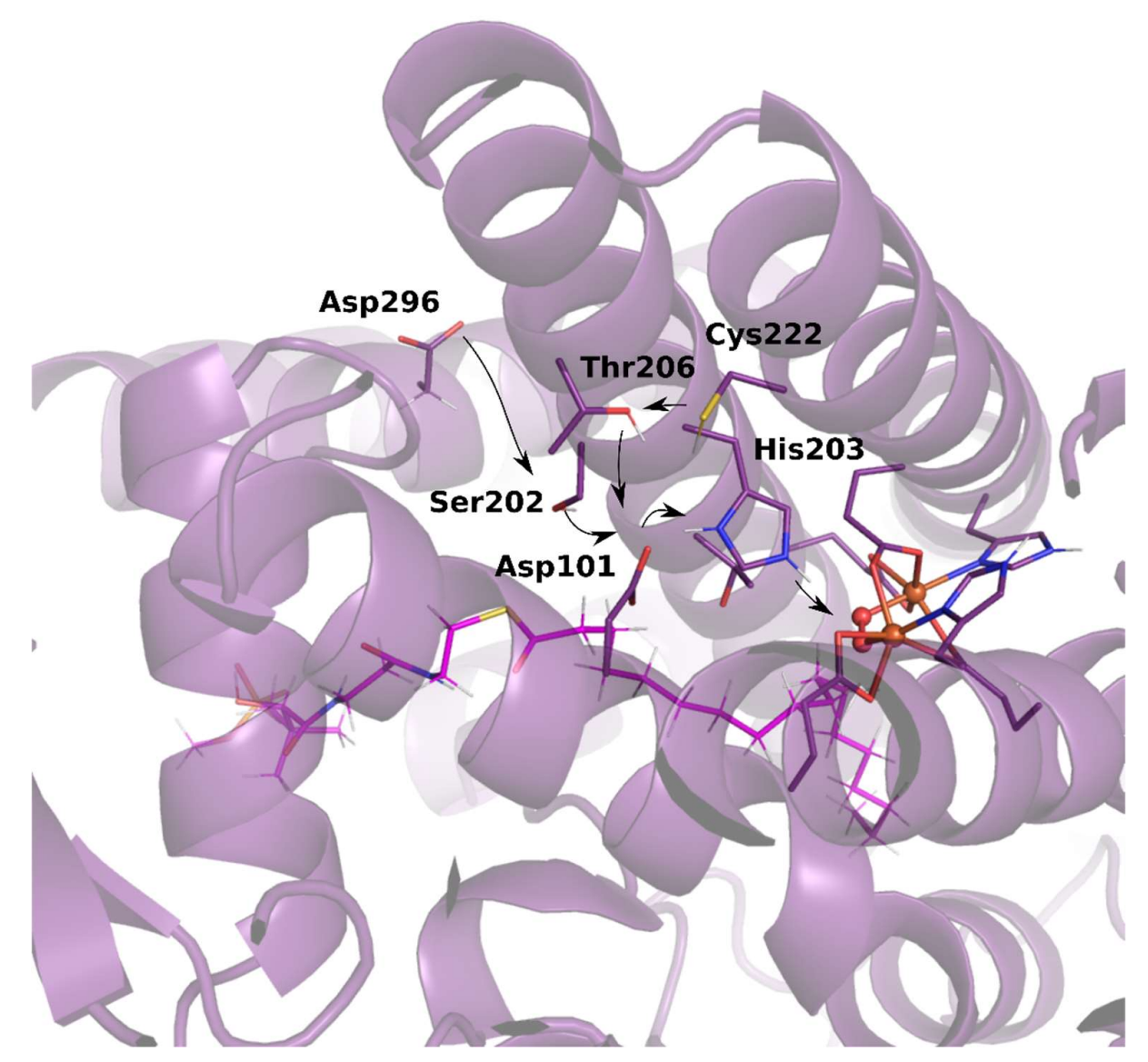


Figure S6. Active site of the $\Delta^{9} \mathrm{D}$ (purple) is overlayed with that of the T4MO enzyme (turquoise). Coordinating residues in $\Delta^{9} \mathrm{D}$ and residues important for the proton transfers to the active sites are highlighted.

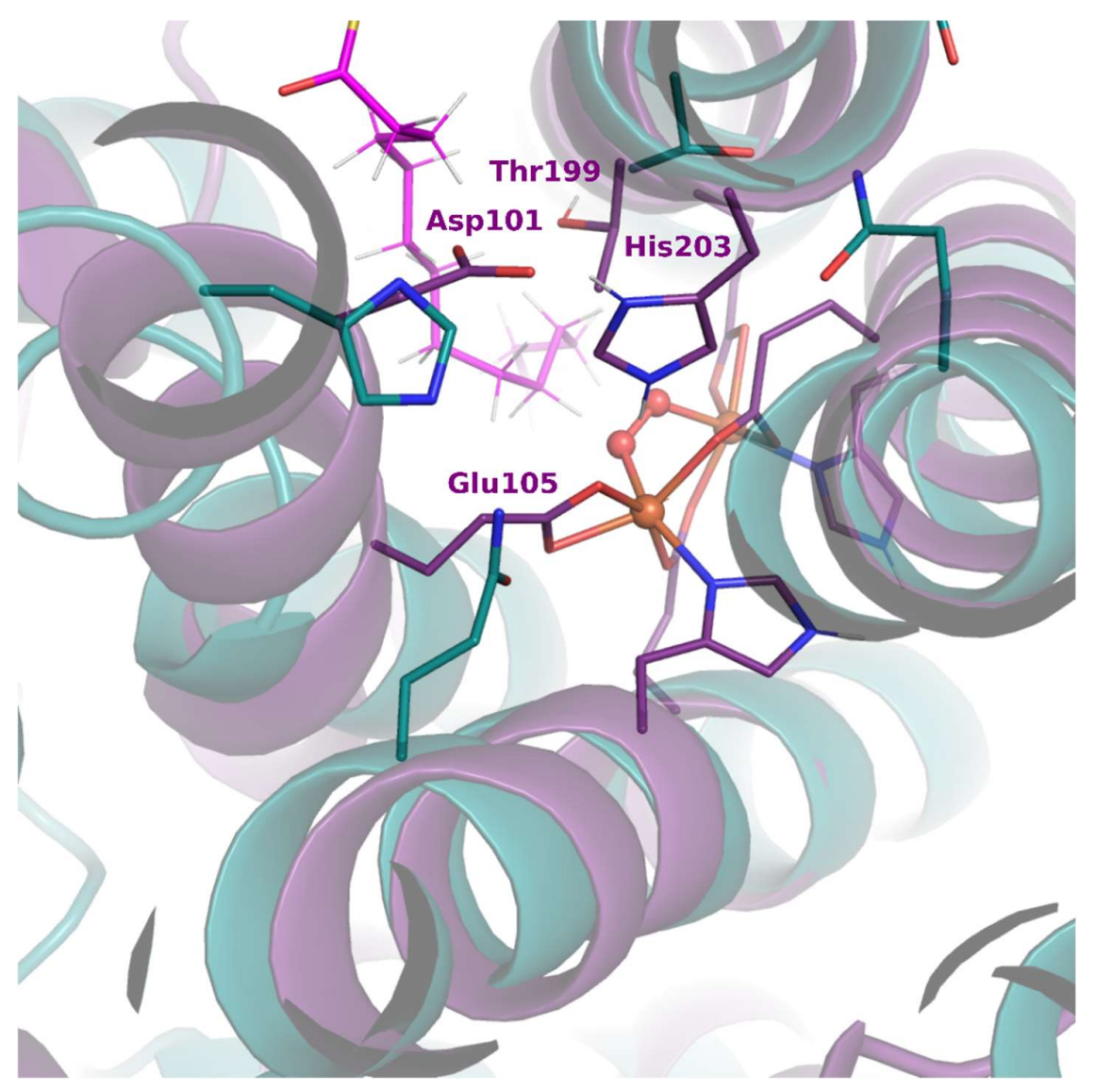


Figure S7. Active site of the $\Delta^{9} \mathrm{D}$ (purple) is overlayed with that of the AurF enzyme (black). Coordinating residues in $\Delta^{9} \mathrm{D}$ and residues important for the proton transfers to the active sites are highlighted. Although no equivalents of Asp101, Thr199, and His203 are present in AurF, there exists an alternative proton transport chain to the coordinating glutamate residue.

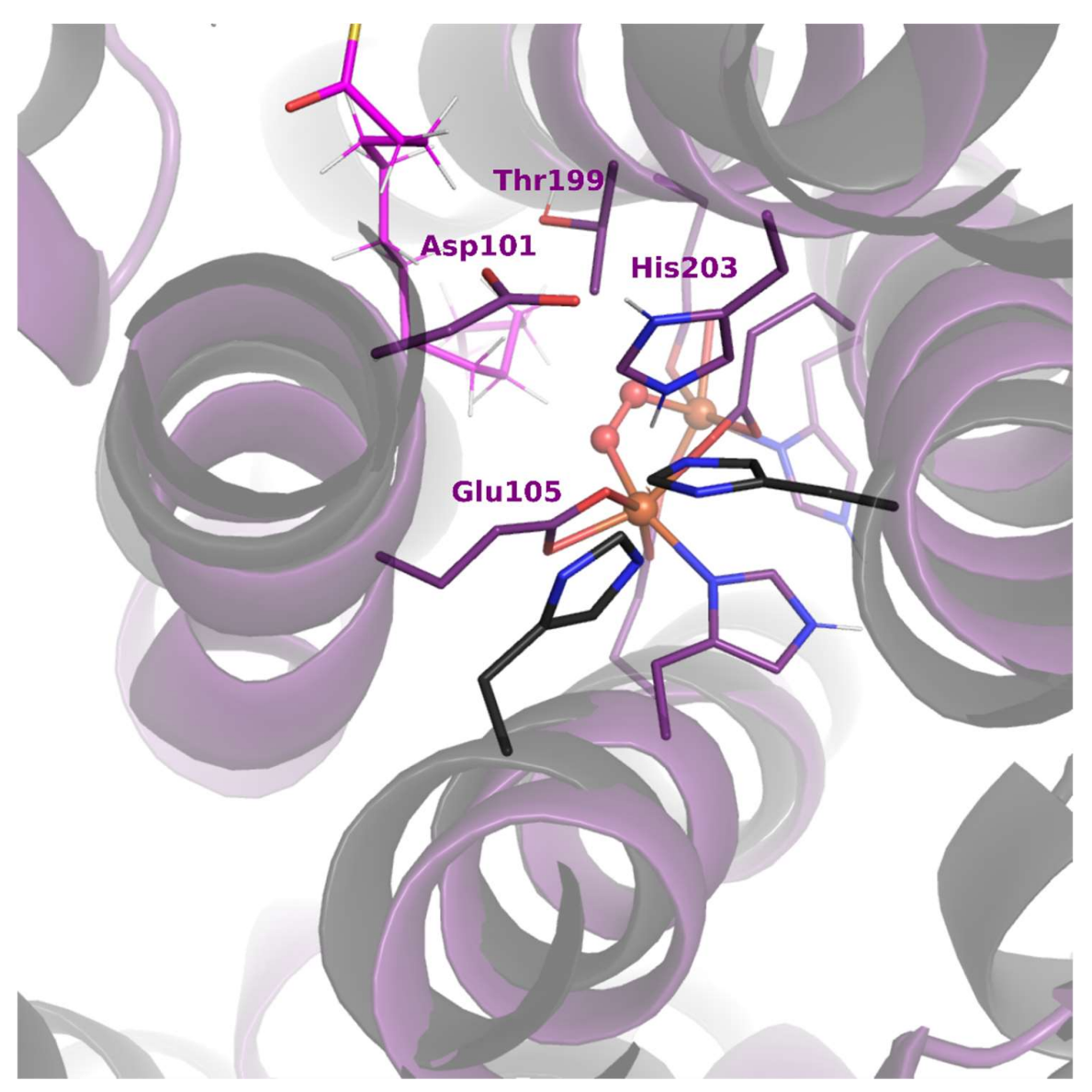


Figure S8. Structure-based multiple sequence alignment (PROMALS3D algorithm - see Computational Details section) of active-site regions of NHFe 2 enzymes: soluble methane monooxygenase (sMMO), benzoyl-CoA epoxidase (BoxB), p-aminobenzoate N-oxygenaze (AurF), toluene monooxygenase (ToMO), rubrerythrin peroxidase (Rbr), ribonucleotide reductase (RNR) and $\Delta^{9}$-desaturase $\left(\Delta^{9} \mathrm{D}\right)$. Important residues of $\Delta^{9} \mathrm{D}$ are highlighted. Core four-helix bundle motif is indicated by cartoon below the sequence, whereas the grey dashed line represents variable structure among different enzymes.
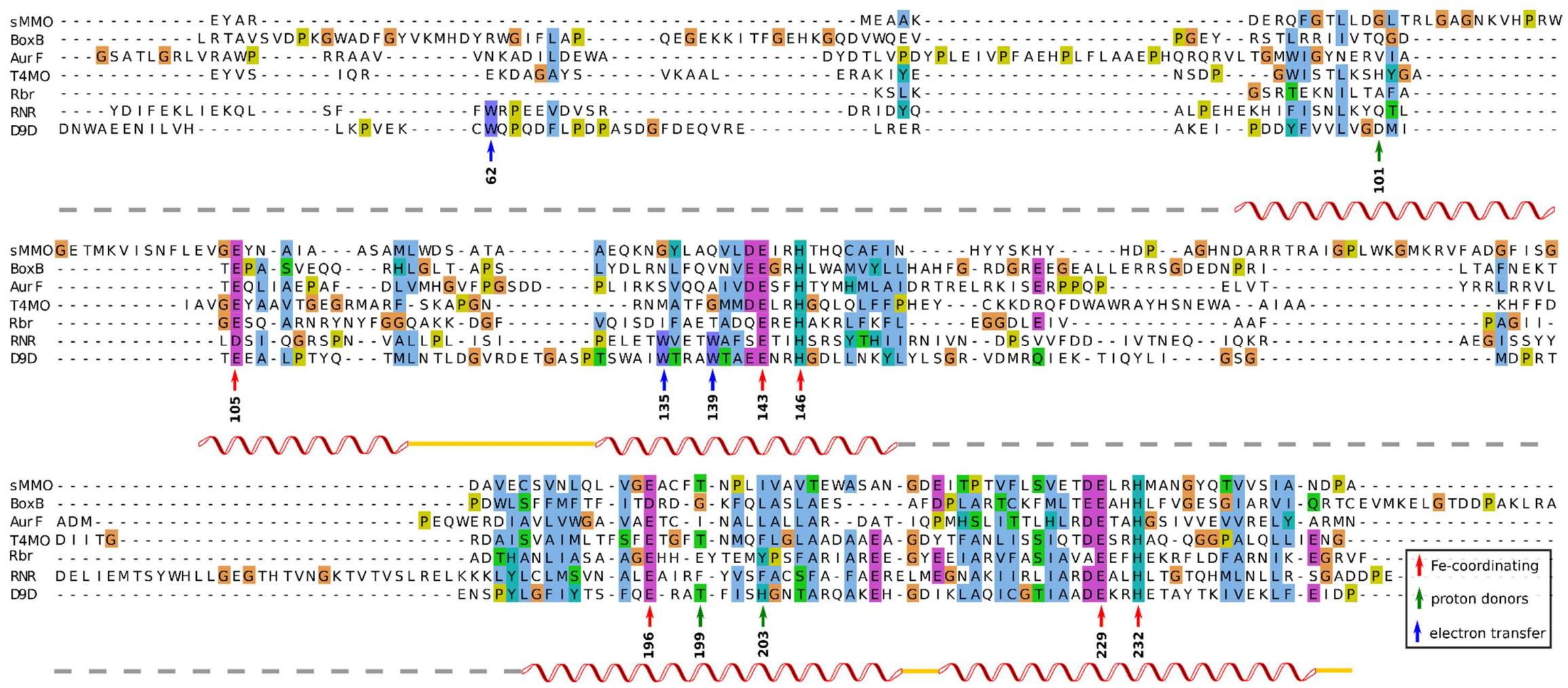
Figure S9. Active site of $\Delta^{9} \mathrm{D} \mathbf{P}$ intermediate. Coordinating residues and the residues suggested as a part of the electron-transfer chain are highlighted.

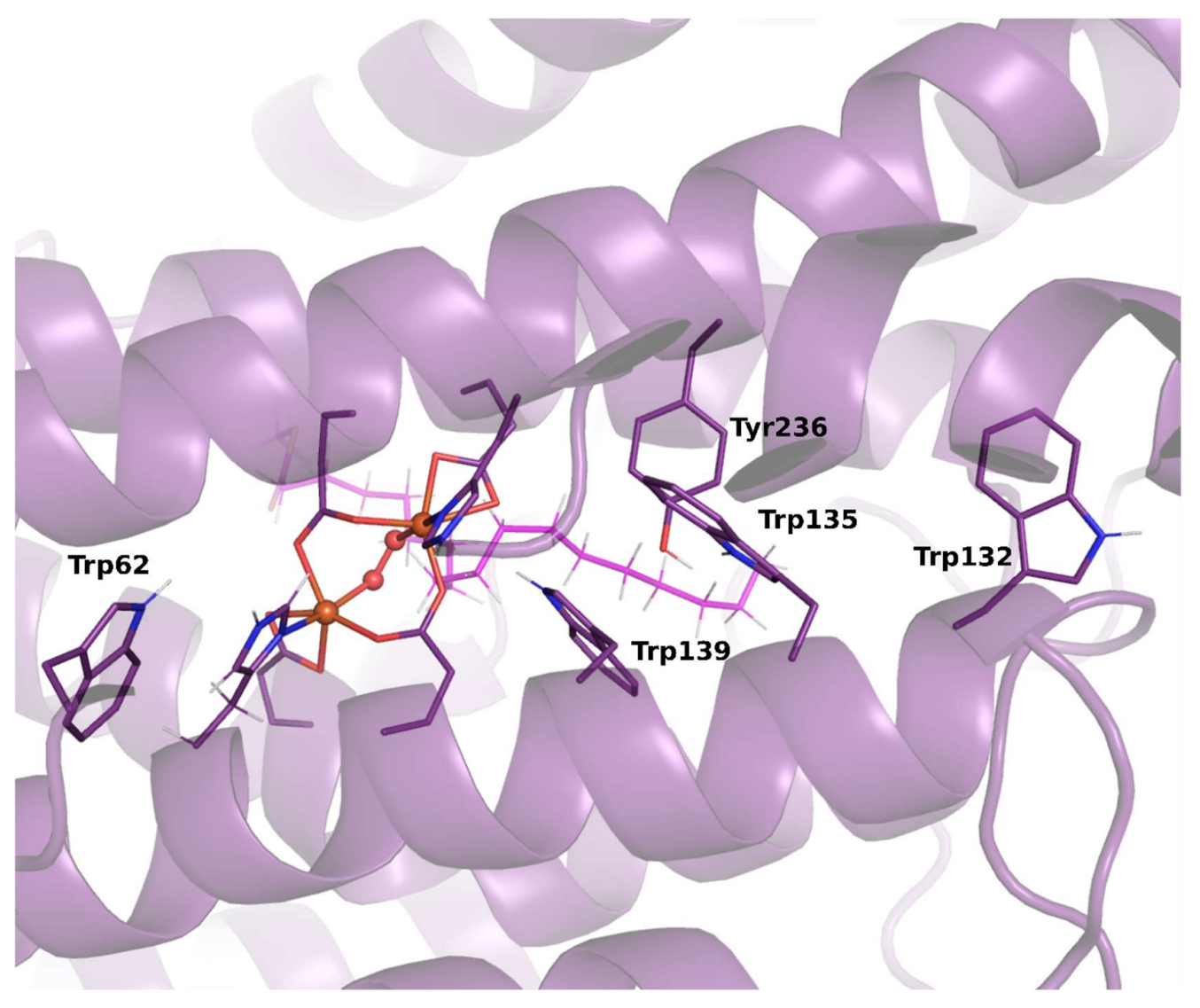

